\title{
The use of mediation as a strategy to enhance the development of cognitive flexibility in self-regulated learning
}

\author{
Salomé Human - Vogel \\ University of Pretoria
}

\begin{abstract}
In this paper I discuss mediation as a possible strategy for enhancing cognitive flexibility in self-regulated learning. Although much has been written on the importance of self-regulated learning there is still much debate about the best way of going about developing it. This paper presents empirical qualitative research that focuses on the creation of a complex learning environment that would facilitate the use of mediation as a teaching strategy to develop children's ability to adapt flexibly to the demands of the learning environment. Learning is viewed as a process of holistic personal development rather than the acquisition of knowledge and skills. As part of the design experiment, the Mediational Behaviour Observation Scale (MBOS) was developed to judge the extent to which the researcher's interaction with the learners could be described as mediatory. A qualitative analysis of the MBOS revealed that certain mediatory behaviours were effective in creating a complex learning environment conducive to the development of self-regulated learning. Further interpretative analysis also suggests that mediation can be particularly useful in the development of cognitive flexibility.
\end{abstract}

Key words: mediation, learning environment, cognitive flexibility, self-regulated learning

\section{Introduction}

Self-regulated learning (SRL) is a concept that has received a great deal of attention in educational psychology research in the past decade (Perry, VandeKamp, Mercer \& Nordby, 2002). SRL, also known as self-directed learning, can be described broadly as an increase in knowledge and skills through independent effort from the learner (Gibbons, 2002). It is also recognised that SRL includes aspects of metacognition and motivation (Patrick \& Middleton, 2002), effective strategy use (Paris \& Paris, 2001) and the role of social interaction and context (Meyer \& Turner, 2002). 
Despite considerable agreement that SRL includes cognitive and motivational aspects (Patrick \& Middleton, 2002) that are generally promoted by the acquisition of cognitive strategies, metacognitive discussions and peer tutoring, much uncertainty still exists about the exact reasons why certain students may be more disposed towards regulating their behaviour than others (Paris \& Paris, 2001). One reason may be that SRL is defined too strongly in terms of learning and that not enough attention is being paid to the holistic personal development of the learner, which would require one to also consider personality, as well as social and emotional development. Personality factors are rarely researched in the context of SRL and personality development is even considered by some authors to have little relevance to education (Byrnes, 2002). However, research indicates that personality traits such as introversion and self-sufficiency may be associated with a disposition towards independent study, whereas personality factors such as dominance may be associated with rigid thought processes and an intolerance of the views of others (Cattell, 1989). Personality factors can also mediate children's acquisition of social skills. Sanz de Acedo Lizarraga, Ugarte, Elawar, Iriarte and Sanz de Acedo Baquedano (2003) report that empathy and assertiveness are important components of self-regulation because children who lack self-regulation skills not only perform poorly on academic measures, they also tend to have more behaviour problems and difficulties in their social relations. Empathy is particularly important in the context of SRL since children are generally required to negotiate with others in a collaborative and social process. Similarly, assertiveness is an important skill that allows children to feel confident in their social interactions with others (Sanz de Acedo Lizarraga et al., 2003). In this article, I will argue that mediation can be used not only to mediate the cognitive skills and strategies associated with SRL, but also address the aspects of emotional development that appear to be associated with SRL.

\section{What can teachers do to help children become self-regulated learners?}

An issue in SRL that remains problematic is whether teachers should teach directly the skills children need to become self-regulated learners, or whether they should provide learning opportunities that require children to develop skills in selfregulated learning. Teachers can therefore either follow an acquisition model of SRL or an emergent model of SRL. Where the former emphasises the acquisition of cognitive and metacognitive strategies, the latter is focused on creating opportunities that require children to develop these skills.

Paris and Paris (2001) suggest that SRL can develop indirectly through experience, directly through instruction and through engagement in practices that require 
self-regulation, but also say that these three methods will probably operate together in classrooms as children engage in school work. An analysis of teacherstudent interactions that foster SRL has led Perry et al. (2002) to conclude that children engage in SRL in classrooms where they have the opportunity to engage in complex open-ended activities, make choices, control challenge and evaluate themselves and others. Specifically, Perry et al. (2002) have observed that teachers can provide instrumental support to children in the form of questioning, clarifying, modeling and so on, and also create opportunities for children to support one another.

However, the question that we need to ask is whether teachers should be confined to addressing SRL in a learning context only, or whether a broader approach should be adopted in which children's personal development is addressed holistically. Vauras, Rauhanummi, Kinnunen and Lepola (1999) report that early metacognitive and motivational readiness are important aspects of strategy training and that higher psychological and motivational vulnerability leads to resistance in some children, making it more difficult for them to benefit from cognitive intervention. Carr and Claxton (2002) suggest that the development of resilience, playfulness and reciprocity may be important dispositions necessary for effective learning. Carr and Claxton (2002) define resilience as the inclination to take on learning challenges where the outcome is uncertain and playfulness as the readiness, willingness and ability to perceive or construct variations in learning situations as well as creativity in the interpretation and response to problems. Reciprocity requires an awareness and willingness to learn from others (Carr \& Claxton, 2002).

The dispositions that Carr and Claxton (2002) describe points to the opposite of psychological vulnerability, which may be described as psychological robustness. In this article I will explore the merit of mediation as a strategy for the development of psychological robustness in the context of SRL, as well as consider how psychological robustness may reveal itself in SRL learning opportunities.

\section{The study}

\section{Research design}

The study reported on in this article employed a design experiment approach to incorporate both quantitative and qualitative elements in the study. Design 
experiments are frequently used to create complex contexts for the research of context-based mathematical problem-solving where the goal is to transform learners into more active, strategic problem solvers (Verschaffel, De Corte, Lasure, Van Vaerenbergh, Bogaerts \& Ratinckx, 1999).

The aim of the design experiment was to create a complex learning environment necessary for the emergence of self-regulatory behaviour. A complex learning environment promotes active participation through social interaction (Vosniadou, loannides, Dimitrakopoulou \& Papademetriou, 2001; Perry et al., 2002), requires learners to respond creatively to the demands of a real-world learning situation, creates an ambiguous problem-space that stimulate the psychological disequilibrium needed for self-organisation (Masterpasqua \& Perna, 1997) and requires a dynamic interaction between learners and their environment (Cilliers, 1998).

A poster was used to mediate the discussion between the researcher and a group of children in the first three years of their school career. The groups were diverse in terms of first language and all of the children were learning in English as the language of learning and teaching (ELoLT). The poster shown in Figure 1 was used to elicit the use of cognitive skills in a realistic, complex environment. The interaction between the researcher and the participants was not structured around pre-defined problems, although several cognitive skills were formulated from the outset and were implicitly present in the researcher's frame of reference. They were knowledge acquisition skills (e.g. comparing and contrasting, classificational skills), metacognitive skills (e.g. focusing, planning, controlling, checking) and critical thinking skills (e.g. formulating personal opinions and beliefs, examining alternative viewpoints).

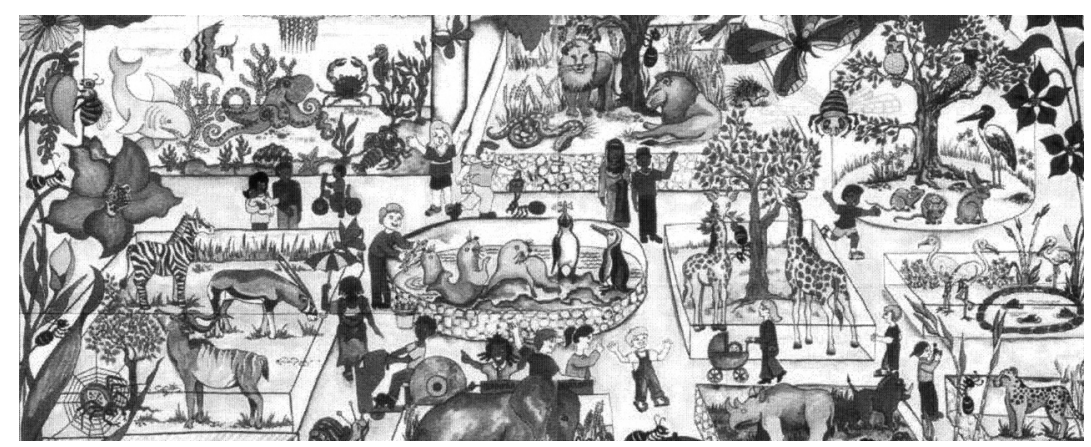

Figure 1 Poster used to mediate discussion 
The instructional technique that was used during the design experiment was strongly influenced by theories of mediation in cognitive intervention literature (Vygotsky, 1978; Feuerstein et al., 1980; Feuerstein et al., 1991; Kozulin \& Presseisen, 1995). Behaviours associated with mediation were operationalised in the Mediational Behaviour Observation Scale (MBOS), which was specially designed for the purpose of the study. Behaviours on the left (positive side) of the MBOS were considered as evidence of a mediational interactional style, whereas behaviours on the right (negative side) were considered to be those that bear evidence of a non-mediatory style of interaction. The MBOS is shown in Figure 2 .

\begin{tabular}{|c|c|c|c|}
\hline School: & Grade: & Date: & Time: \\
\hline $\begin{array}{l}\text { Research } \\
\text { understa } \\
\text { structure }\end{array}$ & dge & \multicolumn{2}{|c|}{$\begin{array}{l}\text { Researcher behaviours that impede } \\
\text { understanding of learners' knowledge } \\
\text { structures }\end{array}$} \\
\hline $\begin{array}{l}\mathrm{KS} 1+\text { : Th } \\
\text { by asking } \\
\text { are learni } \\
\text { request } \mathrm{p} \\
\text { and expe }\end{array}$ & $\begin{array}{l}\text { learners } \\
\text { they } \\
\text { ts which } \\
\text { ledge }\end{array}$ & \multicolumn{2}{|c|}{$\begin{array}{l}\text { KS1-: The researcher interacts with learners } \\
\text { by giving instructions which learners must } \\
\text { follow. }\end{array}$} \\
\hline $\begin{array}{l}\mathrm{KS} 2+: \text { Th } \\
\text { that requ } \\
\text { the form }\end{array}$ & $\begin{array}{l}\text { estions } \\
\text { ners in } \\
\text { ponse. }\end{array}$ & \multicolumn{2}{|c|}{$\begin{array}{l}\text { KS2-: The researcher asks mainly closed } \\
\text { questions which require one-word } \\
\text { responses. }\end{array}$} \\
\hline $\begin{array}{l}\mathrm{KS} 3+: \mathrm{Th} \\
\text { behind le } \\
\text { as a basis }\end{array}$ & $\begin{array}{l}\text { inking } \\
\text { s them }\end{array}$ & \multicolumn{2}{|c|}{$\begin{array}{l}\text { KS3-: The researcher accepts learners' } \\
\text { responses without any further inquiry. }\end{array}$} \\
\hline $\begin{array}{l}\text { KS4-: The } \\
\text { ambiguo } \\
\text { requiring } \\
\text { Research } \\
\text { of cogniti }\end{array}$ & without & \multicolumn{2}{|c|}{$\begin{array}{l}\text { KS4-: The researcher accepts vague, } \\
\text { ambiguous statements from learners } \\
\text { without requiring evidence for statements. } \\
\text { Researcher behaviours that promote the } \\
\text { use of cognitive skills in learning }\end{array}$} \\
\hline $\begin{array}{l}\text { Research } \\
\text { of cognit }\end{array}$ & the use & \multicolumn{2}{|c|}{$\begin{array}{l}\text { Researcher behaviours that impede the } \\
\text { use of cognitive skills in learning }\end{array}$} \\
\hline $\begin{array}{l}\mathrm{CS} 1+\text { Th } \\
\text { to explor } \\
\text { to think b } \\
\text { someone }\end{array}$ & $\begin{array}{l}\text { earners } \\
\text { learners } \\
\text { hile }\end{array}$ & \multicolumn{2}{|c|}{$\begin{array}{l}\text { CS1-: The researcher allows learners to } \\
\text { approach tasks in a disorganised fashion. }\end{array}$} \\
\hline $\begin{array}{l}\mathrm{CS} 2+: \text { Th } \\
\text { of tasks tc }\end{array}$ & xecution & \multicolumn{2}{|c|}{$\begin{array}{l}\text { CS2-: The researcher requires learners to } \\
\text { do tasks without modelling their execution. }\end{array}$} \\
\hline
\end{tabular}




\begin{tabular}{|l|l|l|l|}
\hline $\begin{array}{l}\text { CS3+: The researcher guides learners in } \\
\text { their thinking and task execution without } \\
\text { showing them the correct way immediately. }\end{array}$ & & $\begin{array}{l}\text { CS3-: The researcher immediately supplies } \\
\text { learners with the correct answer or method } \\
\text { when they encounter difficulty. }\end{array}$ \\
\hline $\begin{array}{l}\text { CS4+: The researcher points out behaviours } \\
\text { that enhance or impede problem solving. }\end{array}$ & & $\begin{array}{l}\text { CS4-: The researcher does not provide } \\
\text { information on behaviours that can enhance } \\
\text { or impede problem solving. }\end{array}$ \\
\hline $\begin{array}{l}\text { Researcher behaviours that promote a } \\
\text { negative learning disposition }\end{array}$ & & $\begin{array}{l}\text { Researcher behaviours that promote a } \\
\text { negative learning disposition }\end{array}$ \\
\hline $\begin{array}{l}\text { LD1+: The researcher engages in positive } \\
\text { interactions with learners, makes empathic } \\
\text { statements to acknowledge and confirm } \\
\text { learner's opinion and conveys a personal } \\
\text { interest in the learner. }\end{array}$ & & $\begin{array}{l}\text { LD1-: The researcher engages in negative } \\
\text { interactions with learners, does not } \\
\text { acknowledge learner's contributions and } \\
\text { shows no personal interest in the learners. }\end{array}$ \\
\hline $\begin{array}{l}\text { LD2+: The researcher engages learners in } \\
\text { discussions and encourages learners to } \\
\text { respond verbally. }\end{array}$ & & & $\begin{array}{l}\text { LD2-: The researcher discourages } \\
\text { discussions with learners in the classroom } \\
\text { and accepts pre-verbal responses such as } \\
\text { pointing, headshaking. }\end{array}$ \\
\hline $\begin{array}{l}\text { LD3+: The researcher accepts partially } \\
\text { correct responses and provides positive } \\
\text { feedback. }\end{array}$ & & $\begin{array}{l}\text { LD3-: The researcher rejects responses that } \\
\text { are partially correct and dismisses/rejects } \\
\text { them as incorrect. }\end{array}$ \\
\hline $\begin{array}{l}\text { LD4+: The researcher attributes success in } \\
\text { learning to intrinsic factors (e.g. the efforts } \\
\text { of the learner, hard work). }\end{array}$ & & $\begin{array}{l}\text { LD5+: The researcher encourages risk-taking } \\
\text { and invites learners to take chances, } \\
\text { encourages learners to use their home } \\
\text { language. }\end{array}$ \\
\hline $\begin{array}{l}\text { learning to extrinsic factors (e.g. luck, easy } \\
\text { work). }\end{array}$
\end{tabular}

Figure 2 The Mediational Behaviour Observation Scale (MBOS)

The MBOS shows that the mediational interaction of the researcher was conceptualised around three core areas, namely mediation of knowledge structures - KS (domain/declarative knowledge), cognitive skills - CS (procedural knowledge), and disposition for critical thinking - LD (conditional knowledge). As Boekaertz (1997) points out, domain, procedural and conditional knowledge are important aspects in the development of self-regulated learning as these types of knowledge underpin metacognition.

In constructing the learning environment, the researcher wanted to create an emotional climate that would encourage learners to participate and take risks. 
The behaviours on the left side of the MBOS are all behaviours that were considered to encourage an open and positive approach to new learning experiences. It was argued that approaching the group session with a curiosity for learners' experiences, and a basic respect for what they know, would help to create a learning environment in which learners would feel they have a contribution to make. Creating a safe psychological space requires the mediator to "connect" with her learners on a personal, social and cultural level. It requires the mediator to show solidarity with her learners (Callendar, 1997) and to create positive experiences that help learners to feel that their experiences are valued. Creating a safe psychological learning space is thought to promote the development of psychological robustness in children and to contribute to the holistic personal development of learners.

\section{Method}

Data were collected by recording the interactions between the researcher and the participants in the nine group sessions that formed part of the design experiment. On the design experiment, the researcher conducted three 40 minute group sessions a day with three groups of children selected from the same Grade 1, 2 and 3 classes that had been observed. The children who participated in the group sessions were newly selected each day and no child attended a group session more than once. This was done to ensure that the conclusions drawn from the study would be informed by a broad experiental base. Table 1 shows the number of learners (from each grade and in total) who participated in the group sessions.

Table 1 Design experiment participants $(n=51)$

\begin{tabular}{|l|c|c|c|c|}
\hline Group & Day 1 & Day 2 & Day 3 & Total (Grade) \\
\hline Grade One & 4 & 5 & 5 & 14 \\
\hline Grade Two & 6 & 8 & 6 & 20 \\
\hline Grade Three & 4 & 6 & 7 & 17 \\
\hline Total (learners) & 14 & 19 & 18 & 51 \\
\hline
\end{tabular}

All the recorded group sessions were subsequently transcribed. The verbatim transcriptions of the interaction during the group sessions on the design experiment generated nine discrete data subsets which, together, formed the main data source for the study. The data subsets are summarised in Table 2. 
Table 2 Data subsets (DS)

\begin{tabular}{|l|c|c|c|}
\hline Grades & Day One & Day Two & Day Three \\
\hline Grade 1 & DS1 $(n=4)$ & DS4 $(n=5)$ & DS7 $(n=5)$ \\
\hline Grade 2 & DS2 $(n=6)$ & DS5 $(n=8)$ & DS8 $(n=6)$ \\
\hline Grade 3 & DS3 $(n=4)$ & DS6 $(n=6)$ & DS9 $(n=7)$ \\
\hline
\end{tabular}

The transcriptions were analysed with ATLAS/ti, "a powerful workbench for the qualitative analysis of large bodies of textual, graphical and audio data" (Muhr, 1997). The MBOS categories (as they appear in Figure 1, e.g. KS1+, CS1+, LD1+ and so on) and their descriptions were created as codes on ATLAS/ti, and they were used in interpreting the researcher's utterances. Codes were therefore not generated from the data in the course of analysis, but were pre-defined and fitted to the data by means of open coding, axial coding and selective coding as discussed by Smith (2002).

The consistency rate with which utterances had been coded ranged from $64.64 \%$ (DS6) to $74.46 \%$ (DS2). The overall mean re-coding consistency for all the transcriptions was $70.23 \%$, which was regarded as acceptable. Table 3 shows the coding consistency rates across the nine data subsets.

Table 3 Re-coding consistency rates for DS1 - DS9 (=70.23\%)

\begin{tabular}{|l|c|c|c|c|c|c|c|c|c|}
\cline { 2 - 11 } \multicolumn{1}{c|}{} & \multicolumn{3}{c|}{ Day 1 } & \multicolumn{3}{c|}{ Day 2} & \multicolumn{3}{c|}{ Day 3} \\
\cline { 2 - 11 } \multicolumn{1}{c|}{} & DS1 & DS2 & DS3 & DS4 & DS5 & DS6 & DS7 & DS8 & DS9 \\
\hline Nr of utterances in DS & 162 & 113 & 184 & 168 & 159 & 168 & 132 & 132 & 184 \\
\hline Nr of utterances re-coded & 79 & 56 & 62 & 78 & 83 & 73 & 69 & 63 & 82 \\
\hline Utterances re-coded (\%) & 48.76 & 49.55 & 33.69 & 46.42 & 52.20 & 43.45 & 52.27 & 47.72 & 44.56 \\
\hline Consistency (\%) & 71.51 & 74.46 & 70.40 & 67.13 & 74.44 & 64.64 & 74.42 & 66.47 & 68.68 \\
\hline
\end{tabular}

\section{Results}

\section{Mediational learning environment}

To investigate whether the learning environment that was created by the researcher during the group sessions could be classified as mediatory, the frequencies with which mediatory and non-mediatory behaviours were coded, were obtained. Table 4 indicates the extent to which the researcher's interaction with the children could be regarded as mediatory. 
Table 4 Frequencies of revised MBOS codes across all data subsets

\begin{tabular}{|c|c|c|c|c|c|c|c|c|c|c|c|}
\hline Code & Shortened description & DS1 & DS2 & DS3 & DS4 & DS5 & DS6 & DS7 & DS8 & DS9 & Tot \\
\hline CS1+ & Systematic exploration of tasks & 30 & 36 & 51 & 10 & 38 & 30 & 29 & 31 & 44 & 299 \\
\hline CS1 - & Allows disorganised approach & $\mathbf{0}$ & $\mathbf{0}$ & $\mathbf{0}$ & $\mathbf{0}$ & $\mathbf{0}$ & $\mathbf{0}$ & $\mathbf{0}$ & $\mathbf{0}$ & $\mathbf{0}$ & $\mathbf{0}$ \\
\hline $\mathrm{CS} 2+$ & Modelling task execution & 0 & 5 & 1 & 0 & 0 & 3 & 2 & 0 & 1 & 12 \\
\hline CS2- & $\begin{array}{l}\text { Absence of modelling } \\
\text { execution }\end{array}$ & $\mathbf{0}$ & $\mathbf{0}$ & $\mathbf{0}$ & $\mathbf{0}$ & $\mathbf{0}$ & $\mathbf{0}$ & $\mathbf{0}$ & $\mathbf{0}$ & $\mathbf{0}$ & $\mathbf{0}$ \\
\hline $\mathrm{CS} 3+$ & Guidance in task execution & 84 & 55 & 76 & 72 & 91 & 62 & 86 & 75 & 112 & 713 \\
\hline CS3- & $\begin{array}{l}\text { Immediately supplies } \\
\text { correct answer }\end{array}$ & $\mathbf{0}$ & $\mathbf{0}$ & $\mathbf{0}$ & 2 & 3 & 2 & 1 & $\mathbf{0}$ & 0 & 8 \\
\hline CS4+ & $\begin{array}{l}\text { Enhancing/Impeding } \\
\text { behaviours }\end{array}$ & 3 & 0 & 7 & 2 & 4 & 1 & 1 & 3 & 6 & 27 \\
\hline CS4- & $\begin{array}{l}\text { Absence of enhancing/ } \\
\text { impeding }\end{array}$ & $\mathbf{0}$ & $\mathbf{0}$ & $\mathbf{0}$ & $\mathbf{0}$ & $\mathbf{0}$ & $\mathbf{0}$ & $\mathbf{0}$ & $\mathbf{0}$ & $\mathbf{0}$ & $\mathbf{0}$ \\
\hline $\mathrm{KS} 1+$ & $\begin{array}{l}\text { Opinion/prior knowledge/15 } \\
\text { experiences }\end{array}$ & 7 & 24 & 10 & 6 & 20 & 3 & 4 & 8 & 97 & \\
\hline KS1- & Gives instructions only & 7 & 10 & 12 & 12 & 13 & 13 & 9 & 9 & 7 & 92 \\
\hline KS2- & Closed questions & 95 & 49 & 78 & 112 & 83 & 75 & 51 & 59 & 88 & 690 \\
\hline $\mathrm{KS} 2+$ & Open questions & 31 & 22 & 23 & 26 & 22 & 29 & 40 & 20 & 37 & 250 \\
\hline $\mathrm{KS} 3+$ & Probing learners' responses & 48 & 7 & 15 & 25 & 15 & 17 & 24 & 19 & 23 & 193 \\
\hline KS3- & $\begin{array}{l}\text { Accepts responses without } \\
\text { inquiry }\end{array}$ & 7 & 2 & 10 & 7 & 10 & 7 & 7 & 5 & 11 & 66 \\
\hline KS4+ & Models analytical thinking & 32 & 8 & 15 & 26 & 16 & 17 & 33 & 26 & 21 & 194 \\
\hline KS4- & Vague/ambiguous statement & $\mathbf{0}$ & $\mathbf{0}$ & 8 & $\mathbf{0}$ & $\mathbf{0}$ & $\mathbf{0}$ & $\mathbf{0}$ & 1 & $\mathbf{0}$ & 9 \\
\hline LD1+ & Positive interactions & 27 & 24 & 41 & 27 & 30 & 24 & 26 & 28 & 27 & 254 \\
\hline LD1- & Negative interactions & $\mathbf{0}$ & $\mathbf{0}$ & $\mathbf{0}$ & $\mathbf{0}$ & $\mathbf{0}$ & $\mathbf{0}$ & $\mathbf{0}$ & $\mathbf{0}$ & 2 & 2 \\
\hline LD2+ & Engaging learners in discussion & 64 & 47 & 66 & 90 & 47 & 40 & 60 & 53 & 53 & 520 \\
\hline LD2- & Discouraging discussions & 0 & 2 & 0 & 0 & 2 & 0 & 6 & 6 & 1 & 17 \\
\hline LD3+ & $\begin{array}{l}\text { Accepts partially correct } 9 \\
\text { responses }\end{array}$ & 10 & 11 & 7 & 14 & 14 & 7 & 3 & 9 & 84 & \\
\hline LD3- & $\begin{array}{l}\text { Rejects patially correct } \\
\text { responses }\end{array}$ & $\mathbf{0}$ & $\mathbf{0}$ & $\mathbf{0}$ & $\mathbf{0}$ & $\mathbf{0}$ & $\mathbf{0}$ & $\mathbf{0}$ & $\mathbf{0}$ & $\mathbf{0}$ & $\mathbf{0}$ \\
\hline LD4+ & Intrinsic factors in success & 2 & 5 & 1 & 2 & 3 & 0 & 2 & 0 & 1 & 16 \\
\hline LD4- & Extrinsic factors in success & $\mathbf{0}$ & 1 & $\mathbf{0}$ & $\mathbf{0}$ & $\mathbf{0}$ & $\mathbf{0}$ & $\mathbf{0}$ & $\mathbf{0}$ & $\mathbf{0}$ & 1 \\
\hline LD5+ & Encourages risk-taking & 4 & 3 & 8 & 3 & 11 & 4 & 2 & 4 & 3 & 42 \\
\hline LD5- & Discourages risk-taking & $\mathbf{0}$ & $\mathbf{0}$ & $\mathbf{0}$ & $\mathbf{0}$ & $\mathbf{0}$ & $\mathbf{0}$ & $\mathbf{0}$ & $\mathbf{0}$ & 1 & 1 \\
\hline
\end{tabular}

Table 4 shows that the codes that were allocated the most are CS3+ (Guidance in task execution, 713 times, e.g. Okay, how can we check and make sure it is six?), followed by KS2- (Closed questions, 690 times, e.g. Are they different in their size?) and LD2+ (Engaging learners in discussion, 520 times, e.g. Do you think an ostrich is purple, Sizwe?). Considering the complexity of the learning environment that was constructed and the importance of mediation as the primary instructional strategy, the high frequency of CS3+ and LD2+ is certainly to be 
expected. Other mediatory behaviours that were recorded with a high frequency include CS1+ (Systematic exploration of tasks, 299 times, e.g. Can you see when we do things all at once that we don't get anything right? Okay, what would be a better way to do this?), KS2+ (Open questions, 250 times, e.g. How do we know it's a leopard?), KS4+ (Modeling analytical thinking, 194 times, e.g. What's the difference between a tiger and a leopard?) and KS3+ (Probing learners' responses, 193 times, e.g. She's cross. Why do you think she is cross?).

The low frequency of non-mediatory behaviours as operationalised in the MBOS confirms that the learning environment could be characterised as mediatory and that the three cognitive areas that were targeted for mediation, namely knowledge structures, cognitive skills and critical thinking dispositions, were adequately covered.

\section{Mediation of cognitive flexibility}

A qualitative thematic analysis of the data subsets revealed that the researcher's mediation also addressed other non-cognitive areas that are considered to be implicity important in the development of self-regulated learning behaviours. Dialogue 1 represents an example of mediation geared towards the development of cognitive flexibility. The researcher $(\mathrm{SH})$ is engaged in mediating learners' (L) understanding of some of the objects on the poster. Bold text represents metalevel comments about the dynamics of the interaction between the researcher and the learners and text in italics represents an interpretation of a particular utterance.

\section{Dialogue 1 : Cognitive flexibility}

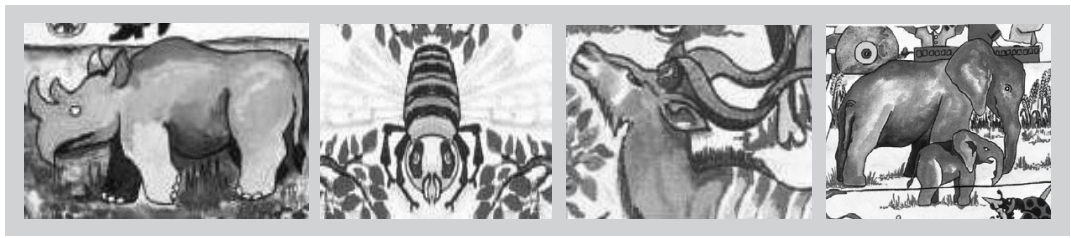

$\mathrm{SH}$ That is great! What is this?

L It's a rhino!

$\mathrm{SH}$ It's a rhino. Yes. What are these funny things on his head? 


\section{Comment}

The researcher involves learners actively in the discussion. When it is apparent that they know what a rhino is, the researcher asks them a question that requires more detailed knowledge. Since the learners in this group are learning in English as the language of learning and teaching (ELoLT), and since the transformation of social speech to inner speech depends to a large extent on language proficiency, the researcher wants to know how effectively learners can verbalise their thinking.

L L Like...it's like a nose. (Transfer of prior knowledge)

L /It's like a nose.

$\mathrm{L} \quad / \ldots$ and he have two eyes, yes.

$\mathrm{SH}$ Yes. Can you see two eyes there? (Accepts response and asks a closed question by repeating child's response.)

L Here, but the other side there's another one. (Recognises dimensionality of representation)

$\mathrm{SH} \quad$ On the other side. Do you think we can call those things on his head horns? (Probes child's thinking in order to understand how her knowledge is organised, and to provide a clue since child does not know the English label. Responsibility still remains with the child to accept or provide an alternative.)

L Yes! They are horns!

L Yes, horns. Like when you get like a cow. (Spontaneous generalisation)

$\mathrm{SH} \quad$ But instead it's here in front. (Differentiation that encourages analytical thinking in the form of comparison.)

\section{Comment}

The researcher invites active participation and develops differentiated understanding using mainly closed questions. Learner shows evidence of selforganisation as he attempts to assimilate this information into his mental model of "animals with horns". Researcher further differentiates by pointing to the difference between a cow's horns and a rhino's horns. In the interaction above, the function of closed questions is to mediate knowledge construction by attending to analytical thinking.

L What is this name?

$\mathrm{SH}$ Show me another animal on this picture that has horns? Which other animals also have horns? 


\section{Comment}

Researcher does not respond to the learner's question and continues her line of questioning. Learners are encouraged to transfer information to other objects. Cognitive flexibility requires learners to generalise existing knowledge to new situations. The question above is an example of what is commonly referred to as 'near transfer' as discussed by Alexander and Murphy (1999).

\section{Here!}

$\mathrm{SH}$ That's right, Nkosi. That one also has horns.

$\mathrm{L} \quad$ Also this one.

$\mathrm{SH}$ This one looks like it... (Learners talking simultaneous/y)

$\mathrm{SH} \quad$ Let's just look at the bee. This one looks like it has horns, but it actually is NOT horns. We call it something else. (Researcher makes learners aware of an anomaly in order to get them to reflect on their current knowledge, and to adapt to the new anomalous information.)

\section{Comment}

One learner generalises his concept of a horn to include the feelers on the bee's mouth. The researcher does not reject the learner's attempt to use her knowledge, but uses it as an opportunity for differentiation and self-organisation. It represents a conscious attempt from the researcher to introduce disequilibrium so that learners can reflect on the viability of their current knowledge, and re-organise it to reflect increasing differentiation and complexity. Such conscious intervention to prompt children to re-organise their experiences reflects a fundamental aspect of mediation.

L Like this. It doesn't bite. This.

L It's a snail!

SH It's a snail.

(Learner says something which is incomprehensible)

$\mathrm{SH}$ The elephant, you said that the elephant has horns. But we... you're right, actually... but we call it another word. (Researcher acknowledges a spontaneous attempt to generalise knowledge and provides support in terms of the child's knowledge of appropriate verbal labels.

L Uhm...uhm...

$\mathrm{SH}$ We call it? Tusks!

L Tusks. 


\section{Comment}

New information leads to differentiation of the concept of "horns" and reorganisation of information. It also shows how ELoLT learners are sometimes thwarted in their attempt to apply their knowledge when their language skills are not fully developed. In terms of mediation, it is important to distinguish between the child's ability to generalise knowledge, and her ability to select and apply the appropriate verbal label. Mediation in terms of vocabulary would probably reflect a lower level of support while mediation in terms of the application of relevant knowledge itself would reflect a higher, more intense level of mediation.

In the dialogue above, the researcher engaged learners in a process of hypothesistesting through social interaction and collaboration. Learners were confronted with concepts that in each case forced them to re-evaluate what they knew and adapt their knowledge if necessary. Such a "trial-and-error" approach is characteristic of complex problem solving where one typically would try out different courses of action or solutions in one's mind before taking actual physical action. As Wood (1998, p. 20) notes, thinking is a substitute for overt actions and permits "trials" whose "errors" are only imagined. In a sense, then, thinking discourages unconsidered, impulsive action and saves time by imagining alternatives and finding the best one before choosing a course of action. Thinking therefore mediates physical action by permitting a psychological response which is literally (and also from an evolutionary viewpoint) aimed at conserving time, energy and effort.

Such cognitive flexibility does not exist from the moment when children are born. Children first learn to adapt to their environment through primitive behaviours such as crying, babbling and squealing, pointing, and so on. At first, the child has no conscious understanding of what these behaviours may mean in a particular culture. Gradually, these behaviours are differentiated and they acquire cultural meaning. The child learns to use these behaviours consciously as a means of achieving certain goals. When this happens, we see the first evidence of the emergence of the psychological mind from biological processes. Crying becomes a way of influencing others' behavior, babbling evolves into a sophisticated cultural system for communication, squealing becomes a way of showing pleasure, pointing becomes a way of expressing needs.

As children master the language of their culture, they change forever the way in which they relate to the physical world by transcending it and constructing a 
psychological universe through which they experience the world. The psychological universe that is constructed can be based only on the children's experience of their physical world and the way in which others mediate the children's experience of the physical world through the use of physical tools and cultural signs. In a sense, all verbal interaction reflects a form of mediation since language is used to organise, direct and transform one's experiences by allowing one to re-construct one's experiences and by creating a past and a future.

Cognitive flexibility requires children to develop an increasingly differentiated understanding of the world around them. With each new situation that children face, confirmations of, and/or exceptions to, their current knowledge arise which they must accommodate in their mental representations. Children's mental representations of the world emerge from interactions with the world on a physical and interactional level. Self-organisation is what makes an emerging psychological mind possible. When discrepancies arise, the information becomes differentiated and learners learn, for example, that not all long, round and pointed external animal appendages are called horns, they can also be feelers, tentacles, or tusks. When learners are sensitised to the finer nuances of their experiences, selforganisation enables them to represent these nuances in their cognitive structures, enhancing their ability for dynamic adaptation to the environment.

Mediation should therefore be used as a tool that allows the mediator to sensitise the learner to the complexities around her so that she may become increasingly flexible in her response to her environment. Mediation can further be viewed as a mechanism through which the child becomes able to respond to the environment with a wide variety of appropriate behaviours. When the mediation takes place in the context of problem-solving, it becomes a way of helping the learner to develop a detailed and differentiated mental representation of the problem. It also helps the child to develop a flexible approach to problem-solving. To this end, it may be very important to create complex environments that allow children sufficient interaction with the mediator and the learning materials. For example, Paris and Paris (2001) report that learners in open-ended environments use more strategies, are more motivated and persist longer in the face of adversity because they were faced with open-ended tasks that required them to be more thoughtful and to derive feelings of self-efficacy as a consequence of their engagement with tasks.

In Dialogue 2 the researcher engages the children in a discussion about birds. The researcher had asked the learners to put beads on all the birds on the poster 
and one bead was put on the bat, indicating that some of the children had not yet developed an accurate representation of the concept of birds.

\section{Dialogue 2 Differentiating concepts}

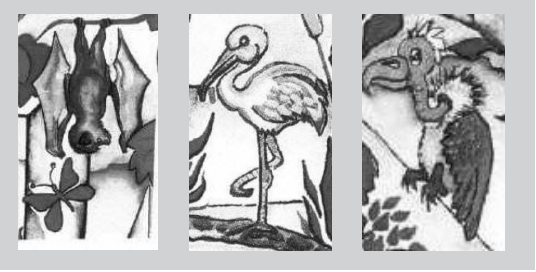

SH Okay, why do you think it is a bird? (Open question to understand learner's personal construct and to encourage child to verbalise his thinking. The researcher foresees that the child will offer some suggestions that will lend themselves to further investigation.)

$\mathrm{L} \quad$ It has wings.

$\mathrm{SH} \quad$ Because it has wings and it can fly? (Extending child's response to introduce a central characteristic, but also to create an opportunity to challenge the belief that all birds can fly. It reflects a conscious attempt to introduce disequilibrium and to force learners to investigate the viability of their knowledge structures.)

$\mathrm{L} \quad$ Because they have wings, because...

\section{Comment}

Researcher questions learner's thinking in order to determine what his mental representation of a bird entails. Since the learner thinks a bat is a bird, the most obvious reason would be that a bat, like a bird, can fly. This points to a vague and undifferentiated representation of the bird-concept, and provides an opportunity for the researcher to challenge the learner's thinking.

SH Okay, why do you say it's not a bird? (Question to a different learner; open question designed to introduce more uncertainty and to use the information as a platform for inquiry.)

$\mathrm{L} \quad$ Because... that thing have nails.

SH Okay, well let me tell you something. He is right. That is not a bird. It can fly like other birds, but do you know what? It doesn't, it doesn't lay eggs! (The researcher's comment provides structure when it becomes evident that the children find it difficult to focus on the defining characteristics of birds.) 


\title{
Comment
}

The researcher attempts to introduce discrepant information through active involvement of another learner. It turns out that the second learner, although his answer is correct, either has an even more primitive concept of what birds are, or may be finding it difficult to communicate his thoughts. The researcher challenges the learners' concept of birds by introducing an additional characteristic of birds: they lay eggs.

L You have something in your hands!

$\mathrm{SH}$ Just a second, just a second. Only animals that can fly, and lay eggs, are called birds.

L Yes. (Support is structured and chaos - disequilibrium - is reduced.)

$\mathrm{SH}$ Only animals that fly and lay eggs. Okay? So this one doesn't lay eggs, and that's why it is not a bird, and you were right. But it is a funny animal, because it can fly.

$\mathrm{L} \quad$ Because... (this learner's comment was lost in the group; his voice was only heard during a playback of the tape.)

\section{Comment}

It frequently happened that some learners' responses were not acknowledged by the researcher. Sometimes, as in the case above, a learner's voice was simply lost in the interaction among various group members. At other times, children interrupted one another, or began a sentence without completing it. At times, it was necessary for the researcher to consciously ignore a learner's attempt if the learner was responding off-task, or if the researcher thought responding would be detrimental to the task at hand. Situations like these do arise frequently in group settings, particularly with young children and should not cause undue concern except when a particular learner withdraws from the group interaction altogether as a result of feeling ignored.

\author{
$\mathrm{SH} \quad$ Are these birds? \\ $\mathrm{L} \quad$ Yes... in the water, it does lay eggs. \\ $\mathrm{SH}$ What lays eggs? \\ L A turtle. \\ SH A turtle? Yes, but it doesn't fly. If it can fly, and if it can lay eggs, both of \\ them, then it's a bird. \\ L But it can lay eggs. That one that stay in the water, it can lay eggs. (This \\ response shows inflexible application and generalisation of a concept by
}


attending to only one feature at a time and is characteristic of children whose cognitive structures show that they have not yet learned to utilise chaos for self-organisation.)

\section{Comment}

As the learner attempts to apply his knowledge to other animals, it becomes apparent that he has only incorporated egg-laying into his mental schema of birds, and so comes to the conclusion that a turtle must also be a bird. Ordinarily, one would often simply dismiss such an answer as incorrect and correct the learner's misconception. However, in terms of complexity theory it provides an opportunity for the researcher to help the learner to adjust and re-organise his mental representation of what a bird is, by helping him to attend to more than one defining characteristic of birds: they fly and they lay eggs.

SH Okay, you're right. A turtle?

L Yes.

$\mathrm{SH}$ You're right, it does lay eggs. Do you know where it lays its eggs? Where? (The researcher decides that further examination of the nature and habits of turtles may provide an opportunity to compare them with birds and may eventually lead to the learner adapting his mental schema of birds.)

L It get out of the water and then... (indecipherable because of noise outside.)

$\mathrm{SH}$ Tell me, do you think a flamingo is a bird? (Closed question functions to introduce another possible source of ambiguity designed to create disequilibrium.)

L No! No!

L It can't fly...(This answer was foreseen and presents an opportunity to further refine children's mental schema of birds.)

L But it stands higher...

SH Who says a flamingo can't fly?

L Me!

$\mathrm{SH}$ Who says the flamingo can fly?

L Me!

$\mathrm{SH} \quad$ Ah! This time you and you are right. A flamingo can fly. An ostrich cannot fly, but a flamingo can fly. So maybe you were thinking of an ostrich? Because an ostrich can't fly. But an ostrich is still a bird.

\section{Comment}

The interaction is temporarily diverted by the egg-laying turtle and then the researcher redirects attention again to add yet another piece of inconsistent 
data: Ostriches cannot fly, yet they are birds. Once again, challenging learners' mental representations with discrepant data forces them to reconsider the viability of their knowledge, and accommodate this additional information by reorganising their representations.

L This is four: one, two, three, four.

$\mathrm{SH}$ Okay, but is this a bird? I want to know if this is a bird (Researcher pointing to flamingo.)

L No, no, it's not a bird.

L It's a flamingo.

$\mathrm{SH}$ But is a flamingo a bird?

L No! (This child resists having to adjust his concept of what a bird is, an example of inflexible cognitive structure where the child has either not learned how to deal with ambiguous or anomalous information, or is limited in her ability to accommodate ambiguity.)

L It's very higher, more higher than a bird.

\section{Comment}

Here it is evident that for one particular learner, a flamingo is not necessarily part of a superordinate class of birds, indicating that the concept is not differentiated enough to capture all the detail. For this particular learner, birds are apparently small, and apparently only small birds can fly. It is therefore possible that it is primarily the size of the flamingo that convinces the learner that the flamingo cannot be a bird.

SH Okay... but, let me tell you a secret: a flamingo is a bird. If you want to know if something is a bird, you must look for three things: it must be able to fly, it must be able to lay eggs...

L Yes?

$\mathrm{SH}$ And... it must have feathers. If it has feathers, you can be sure it is a bird. Anything with feathers is a bird. If it can fly, or if it cannot fly, if it has feathers, it is a bird. Do you believe me? (New information acts to create disequilibrium and learners must accommodate the new information with their current knowledge).

L But... uhm...

L I know that a flamingo fly... I know. 


\section{Comment}

After the introduction of a third dimension - the presence of feathers - it becomes possible for the learners to re-organise their concept of what birds are. Suddenly one learner can say with confidence that a flamingo is indeed a bird. The uncertainty of one learner (But...uhm) indicates that her mental representation of a bird is undergoing change - the new information has created an upheaval in her current thinking and she is as yet uncertain how to accommodate it.

$\mathrm{SH}$ You know that a flamingo flies? So how many birds do we have on this picture? Can you count for us?

L One, two, three, four, five...seven!

$\mathrm{SH}$ Do you agree?

L Yes.

\section{Comment}

The correct number of the birds on the poster is actually nine. The two birds that had been omitted were the penguins in the centre of the poster. Two possible reasons exist for their omission. Firstly, they are spatially removed from the other birds and it could have been an oversight. Secondly, they appear in another context - together with seals in a pond - which might make them appear not to be birds. Further mediation would have revealed which is more likely - but unfortunately the time had expired and the session was terminated.

The interaction between the researcher and the group of learners in Dialogue 2 shows an important aspect of learning as a process of self-organisation, namely questioning of learners' thinking as a tool for guiding the emergent organisation of their cognition. Self-organisation requires a learner to be able to be responsive to a changing and unpredictable environment.

According to Paris and Paris (2001) two metaphors for self-regulated learning exist, one which emphasises self-regulated learning as the acquisition of skills, and the other which focuses on the learner "becoming" a self-regulated learner as s/he develops new competencies. Learning as self-organisation can be aligned with a metaphor of "becoming" rather than "acquiring" because children give meaning to their experiences in unique ways, they learn in unique ways and they need to organise their learning experiences in a way that makes sense to them. Acquiring strategies amounts to little more than training and training does not 
generally lead to authentic understanding and learning because it does not require the active deconstruction and reconstruction of conceptual structures.

\section{Discussion}

This article addressed the use of mediation as a strategy to enhance the development of cognitive flexibility required for self-regulated learning. As the MBOS indicated, the learning environment that was created on the design experiment was sufficiently mediatory to enable it to be classified as such.

The mediational behaviours that were used most often by the researcher included CS3+ (Guidance in task execution), KS2- (Closed questions), LD2+ (Engaging learners in discussion), CS1+ (Systematic exploration of tasks), KS2+ (Open questions), KS4+ (Modeling analytical thinking) and KS3+ (Probing learners' responses).

The mediatory behaviours of the researcher not only mediated an understanding of learners' knowledge structures, use of cognitive skills and positive learning dispositions, they were also instrumental in creating an environment in which learners would feel safe to explore and contribute. When children are encouraged to participate in a discussion and when they are asked about their beliefs and opinions, one can create an atmosphere in which a child not only feels safe to take risks, but increased risk taking among all children can provide the opportunity for children to learn from one another. When children are encouraged through mediation to try out different problem-solving strategies, or to listen to others' attempts at solving a problem, they can not only learn to be assertive about how they learn, but they can also develop empathic skills that are important in critical thinking. Therefore, although mediation generally targets the cognitive skills and strategies that children use and helps them to apply these strategies in a problemsolving context, the increased confidence and risk-taking that comes with such an open and accepting learning environment helps children to develop not only cognitively but also emotionally and socially.

It appears that an emergent model of SRL may be particularly important in the holistic personal development of children as self-regulated learners and that a mediational strategy may be an appropriate tool to achieve such holistic development. Direct instruction of cognitive skills and strategies may be effective in helping children to know what a learning situation requires of them, but when 
the learning environment is structured more openly to provide opportunities for self-regulated learning children can develop emotional and social self-regulation as well. The shared social space which results from interaction between the researcher and the learners forms the setting within which children can re-evaluate their constructions. Meyer and Turner (2002) point out that intersubjectivity is a critical aspect of self-regulated learning and requires methods that can explore the complexities of teacher-learner interactions. Intersubjectivity creates an authentic experience in which children can think and learn collaboratively, and so mutual trust and respect is of prime importance (Meyer \& Turner, 2002).

This study also indicates that mediation may be an important strategy in the development of self-regulation in so far as it promotes cognitive flexibility. Cognitive flexibility refers to the ability of children to generate, select and apply various problem-solving strategies creatively in accordance with the demands of a complex learning task and involves the ability to respond creatively to unexpected demands from the environment.

Flexible problem solving is recognised to be an important aspect of self-regulated learning (Paris \& Paris, 2001) and requires dynamic adaptation to the environment. Mediation aids in dynamic adaptation because it develops children's ability to attend to more than one aspect or dimension of a problem, to develop a differentiated understanding of a situation, and to re-organise one's thinking in response to additional information. However, it may be true that the success of mediation in the development of SRL may depend significantly on the skill of the mediator. Mediation requires a flexible attitude towards learning, a warm responsiveness towards children and a willingness to let the child lead the interaction while the mediator adapts the content of the mediation. Here as well, personality factors may play a role in the mediatory style of the teacher. It stands to argue that those who value structure and predictability in the didactic experience may perhaps not provide as effective mediation as those who can tolerate a fair amount of complexity and uncertainty. This is not to say that mediation relies solely on chaos and unpredictability. Rather, mediation requires responsiveness and flexibility on the part of the mediator so that the learning experience that is created utilises chaos and structure that responds to the child's learning needs.

Meyer and Turner (2002) also point out that the kinds of activities and interaction that self-regulated learning demands remain problematic in classroom settings because of a number of factors. The size of classes, teachers' evaluation of learners' 
responses in class, teachers' limited knowledge of learners' cognitive, emotional, motivational and social competencies and time demands which limit teachers' choice of learning material all constrain teachers' efforts to engage in quality interaction with their learners.

\section{Conclusion}

Mediation requires complex interactions between the system and the environment. Therefore, it makes sense that the learning opportunities which we provide for children should afford the opportunity for complex interactions. When mediation is geared towards the development of cognitive flexibility, a learning environment is created in which knowledge can be negotiated. Learners are not encouraged to view knowledge or problem-solving as fixed entities, but as social constructs which can and should undergo change. Cognitive flexibility may then very well enhance the development of social and emotional flexibility in the sense that children learn to view themselves as agents in the construction of knowledge and skills rather as mere passive recipients of knowledge. Children also learn to approach problem-solving empathically in a social context where the ability to understand other children's point of view becomes an important tool in effective problem-solving.

The development of cognitive flexibility in children requires mediators to question and challenge children to participate actively in learning and, in doing so, communicate that each learner has a contribution to make. Children who are repeatedly exposed to learning experiences that require them to participate, that enable them to acquire and develop a variety of cognitive, emotional and social skills and strategies in a safe and positive environment, would perhaps be much more likely to develop into authentic self-regulated learners than those who are exposed to the formal instruction of SRL skills only. Mediation therefore requires an active involvement in the personal development of the child beyond merely teaching cognitive skills.

A problematic issue that remains to be studied however, concerns the role of language in the mediation of SRL. It is generally recognised that children's language experiences are an important aspect of children's cognitive development (Nelson, 1996). Vygotsky (1930/1978) asserts that social speech is actually internalised and transformed to become mental functions, thus saying that cognition stems from social interaction mediated by language. Hart (2000) also points out that 
children's language experiences are important to cognitive development because the complexity of children's language often influences the complexity of others' responses to them.

Children who learn through the medium of ELoLT, perhaps because the classroom is characterised by great linguistic diversity, often find it difficult to participate in open and flexible learning environments that require a great deal of verbal interaction. It would be worthwhile for future research to address the question of language as a barrier to the development of SRL. Similarly, it could prove fruitful to investigate how mediational strategies may be used to overcome language barriers to learning.

The design experiment reported in this article consisted of small groups of learners, which made it fairly easy to influence emerging patterns of participation among the children. While this may be regarded as a methodological weakness in the research, it also points to the fundamental changes that everyday classroom interaction between teachers and learners need to undergo. The implementation of a cognitive intervention approach that promotes the principles of chaos and complexity would require a fair amount of adaptation and adjustment in regular classrooms.

Frederickson and Cline (2002) note that everyday classroom language is often dominated by the classroom teacher and takes the form of a stylised exchange of questions and answers which tend to reduce the average length of children's utterances by as much as two thirds. Against this background it appears as if mediation as a teaching strategy to enhance cognitive flexibility does not seem to represent an attainable or even realistic teaching goal. To expect teachers to encourage chaos and complexity through mediation would probably entail teachers having to give up their right to begin and end conversational encounters, to ask all the questions, to allocate turns at speaking which they do not claim themselves and to control the framework of the conversation (Frederickson \& Cline, 2002). Many teachers may not be ready to give up their power of determining what happens in the classroom.

Nevertheless, considering that many teachers in South Africa (Taylor, 1999) and other countries (Sternberg \& Martin, 1988) are under the impression that they are teaching thinking when they are not, the research in this article hopes to contribute towards the body of knowledge in cognitive intervention by analysing 
which behaviours teachers should be engaging in if they wish to develop children's self-regulatory learning skills.

\section{References}

Boekaertz, M. 1997. Self-regulated learning: A new concept embraced by researchers, policy makers, educators, educators and students. Learning and Instruction. 7(2), 161-186.

Byrnes, J.P. 2002. Minds, brains and learning. New York: The Guilford Press.

Callendar, C. 1997. Education for empowerment: The practice and philosophies of black teachers. Staffordshire: Trentham Books Limited.

Carr, M. \& Claxton, G. 2002. Tracking the development of learning dispositions. Assessment in Education. 9(1), 9 - 37.

Cattell, H.B. 1989. The 16PF: Personality in depth. Illinois: IPAT.

Cilliers, P. 1998. Complexity and postmodernism. London: Routledge.

Feuerstein, R. 1980. Instrumental Enrichment. An intervention program for cognitive modifiability. Illinois: University Park Press.

Feuerstein, R., Klein, P.S \& Tannenbaum, A.J. (Eds). 1991. Mediated learning experience: Theoretical, psychosocial and learning implications. London: Freund Publishing House Ltd.

Gibbons, M. 2002. The Self-directed Learning Handbook. San Fransisco: JosseyBass.

Kozulin, A \& Presseisen, B.Z. 1995. Mediated Learning Experience and Psychological Tools: Vygotsky's and Feuerstein's Perspectives in a Study of Student Learning. Educational Psychologist. 30, (2), 67 - 75.

Masterpasqua, F. \& Perna, P.A. (eds). 1997. The psychological meaning of chaos. Washington: American Psychological Association.

Meyer, D.K. \& Turner, J.C. 2002. Using instructional discourse analysis to study the scaffolding of student self-regulation. Educational Psychologist. 37(1), 17 -25 .

Muhr, T. 1997. ATLAS.ti: The knowledge workbench. Short User's Manual. Berlin: Scientific Sortware Development.

Nelson, K. 1996. Language in Cognitive Development: The emergence of the mediated mind. Cambridge: Cambridge University Press.

Paris, S.G. \& Paris, A.H. 2001. Classroom applications of research on self-regulated learning. Educational Psychologist. 36(2), 89 - 101.

Patrick, H. \& Middleton, M.J. 2002. Turning the Kaleidoscope: What we see when self-regulated learning is viewed with a qualitative lens. Educational Psychologist. $37(1), 27-39$. 
Perry, N.E., VandeKamp, K.O., Mercer, L.K. \& Nordby, C.J. 2002. Investigating teacher-student interactions that foster self-regulated learning. Educational Psychologist. 37(1), 5 - 15.

Sanz de Acedo Lizarraga, M.L., Ugarte, M.D., Cardelle-Elawar, M., Iriarte, M.D. \& Sanz de Acedo Baquedano, M.T. (2003). Enhancement of self-regulation, assertiveness and empathy. Learning and Instruction. 13 (2003), 423 - 439.

Sternberg, R.J. \& Martin, M. 1988. When teaching thinking does not work, what goes wrong? Teaching thinking. 89(4), 555-572.

Taylor, N. 1999. Getting Learning Right. Report of the President's Education Initiative Research Project. Presentation delivered at the Conference: Educator Development - Connecting Policy and Practice. Department of Education on 18 - 20 May 1999.

Vauras, M., Rauhanummi, T., Kinnunen, R. \& Lepola, J. 1999. Motivational vulnerability as a challenge for educational interventions. International Journal of Educational Research. 31(1999), 515 - 531.

Verschaffel, L., De Corte, E., Lasure, S., Van Vaerenbergh, G., Bogaerts, H. \& Ratinckx, E. 1999. Learning to solve mathematical application problems: A design experiment with fifth graders. Mathematical Thinking and Learning. 1(3), $195-229$.

Vosniadou, S., loannides, C., Dimitrakopoulou, A. \& Papademetriou, E. 2001.

Designing learning environments to promote conceptual change in science. Learning and Instruction. 11 (2001), 381 - 419.

Vygotsky, L.S. 1978. Mind in Society. Cambridge, Massachusetts: Harvard University Press.

\section{Salomé Human - Vogel}

Department of Educational Psychology

University of Pretoria

email: shuman@postino.up.ac.za 